\title{
Questões Críticas do Estatuto da Feminilidade na Contemporaneidade e suas Repercussões
}

\author{
Mauro Pioli Rehbein* \& Daniela Scheinkman Chatelard \\ Universidade de Brasília, Brasília, DF, Brasil
}

\begin{abstract}
RESUMO - Este artigo trata das questões críticas do estatuto da feminilidade na contemporaneidade e destaca as suas dificuldades com a feminilidade e a maternidade. Para abordar esse assunto, foi necessário antes apresentar o estatuto do grande Outro, pois a psicanálise considera o declínio da função paterna simbólica como a principal premissa para investigação das mutações culturais. A partir desse declínio, o grande Outro da modernidade caracteriza-se pelo esvaziamento das referências simbólicas e da mudança da sociedade patriarcal para a matriarcal. Caracterizado pelo domínio materno, o estatuto da feminilidade resulta na primazia do gozo feminino e do supereu, bem como nas condições críticas da falta, do desejo, das dificuldades com a maternidade e do mal-estar na cultura.
\end{abstract}

PALAVRAS-CHAVE: estatuto do outro, estatuto da feminilidade, função paterna simbólica, maternidade

\section{Critical questions of the Femininity Statute in contemporaneity and repercussions thereof}

\begin{abstract}
This paper addresses the critical questions of the Femininity Statute in contemporaneity and emphasizes its difficulties concerning both Femininity and maternity. Before that task is accomplished the Statute of the big Other is presented for psychoanalysis regards the decline in the symbolic paternal function as the main premise to investigate cultural mutations. Upon that decline the big Other in modernity is characterized by emptying of the symbolic references and the transition from a patriarchal to matriarchal society. Under maternal dominance the Femininity Statute results in the primacy of the female and superego jouissance as well as in the lack critical conditions, desire, difficulties with maternity and cultural discontent.
\end{abstract}

KEYWORDS: other statute, femininity statute, symbolic paternal function, maternity

O objetivo deste artigo é apresentar algumas das facetas críticas importantes do estatuto da feminilidade na contemporaneidade, destacar algumas consequências e dificuldades com a feminilidade em decorrência desse estatuto, sobretudo com a reprodução e a maternidade. Essas questões críticas e complexas são oportunas para aprofundarmos essas discussões sobre fatos clínicos e demonstrarmos que esse viés do estatuto da feminilidade proposto não é um fenômeno social isolado, mas está correlacionado ao estatuto do grande Outro. O declínio do pai simbólico, do significante Nome-do-Pai, é considerado pela psicanálise lacaniana como a principal premissa para abordarmos as dificuldades encontradas com a mutação cultural na contemporaneidade.
O tema abordado é o da feminilidade em interseção com o campo do grande Outro. O recorte proposto restringe-se às questões críticas da relação de ligação mãe-filha e suas repercussões, tais como a da falta, do desejo, das relações amorosas e, sobretudo, da dificuldade com a maternidade. A temporalidade dos estatutos do Outro e, por conseguinte, da feminilidade, estão delimitados à modernidade e seus reflexos na contemporaneidade, em razão de suas características mais críticas tornarem-se significativas, com o declínio da função paterna simbólica. Esse declínio ocorre justamente a partir de mudanças sociais, políticas e econômicas advindas da modernidade.

O significante Nome-do-Pai é essencial na estrutura para o nascimento do sujeito, como efeito de significantes.

\footnotetext{
*E-mail: maurorehbein@gmail.com

— Submetido: 17/03/2016; Revisado: 12/08/2016; Aceito: 05/01/2017
} 
O declínio desse significante é central para apontarmos as novas configurações dos estatutos do Outro e da feminilidade. Acerca disso, fizemos algumas articulações com o complexo de Édipo e com a castração para demonstrarmos a importância e a dificuldade de algumas vivências e, sobretudo, dos estragos na estrutura e suas consequências para o estatuto da feminilidade. Do contrário, não poderíamos entender os determinantes dos fatos e problemas apontados em relação aos estragos, à feminilidade e à maternidade. A função paterna simbólica foi fundamentada essencialmente em Lacan e algumas referências a Jerusalinsky (2004) e Julien (1997).

O estatuto do grande Outro, como veremos, está marcado pelo declínio do pai simbólico e pela transição de uma sociedade patriarcal para uma sociedade matriarcal. Ademais, marcado pelo esvaziamento simbólico do grande Outro, caracterizado pelas perdas das referências, pela ascensão do capitalismo e o consumo. Com isso, uma das consequências nefastas é o rechaço à castração. Esse percurso é realizado tendo como referências Freud, Lacan, Melman, Sobral e Rassial.

$\mathrm{O}$ estatuto da feminilidade na contemporaneidade é marcado pela ascensão do matriarcado. O predomínio da presença materna nos núcleos familiares intensifica a relação de ligação mãe-filha, favorecendo a prevalência da identificação narcísica e ao imperativo do gozo superegoico materno. Pois, o que teria força de anteparo entre elas está em declínio, a metáfora paterna. Por consequência, esse estatuto é caracterizado pelo rechaço à feminilidade. Os principais autores que contribuem para apresentar os pontos críticos e as dificuldades encontradas no estatuto da feminilidade na contemporaneidade são: Lacan, Zalcberg, Guimarães, Sobral, Melman, Eliacheff e Heinich, Naour e Calligaris.

As questões críticas dos estatutos apresentados asseveremos que estão diretamente relacionadas com as dificuldades encontradas com a maternidade. A maternidade diz de uma mãe, a feminilidade de uma mulher, são desejos distintos, porém não excludentes, são dois gozos, respectivamente, o gozo fálico e gozo feminino, mas além do falo, o gozo Outro. As dificuldades com a feminilidade afetam as condições de procriação, da maternidade e na produção de mães angustiadas. As referências utilizadas nas articulações foram Lacan, Freud, Zalcberg, Guimarães, Boukobza, Licht, Naouri e This.

Por fim, o objetivo não é salvar o pai, mas evidenciar as dificuldades decorrentes desses estatutos, principalmente as do estatuto da feminilidade e os aspectos negativos que entendemos mais pertinentes e que contribuem para o malestar na contemporaneidade.

\section{O DECLÍNIO DA FUNÇÃO PATERNA}

Em 1938, Lacan chamava de declínio da imago paterna o que seria do registro do imaginário, pois não dispunha ainda de arcabouço teórico constituído a respeito dos registros do imaginário, do simbólico e do real. Mais tarde, com o desenvolvimento dessa função simbólica, vai chamar de o declínio do Nome-do-Pai (Chemama, 2007). Lacan (1938/1987, p. 60) assinala que, em decorrência disso, teria também o declínio da dialética da família, da vida conjugal. Por razões, condiciona-os à concentração econômica e às consequências políticas desastrosas, que contribuem com o cenário social, as constituições dos núcleos familiares e suas relações na contemporaneidade. Curiosamente, o perigo ameaçador no futuro não seria do embrutecimento dos indivíduos, mas das forças tirânicas do supereu.

Para a psicanálise, as constituições das estruturas neuróticas se demonstram dependentes das condições familiares. A grande neurose contemporânea (Lacan, 1938/1987), tem a sua principal determinação na carência da personalidade do pai. Essa imago paterna precária, carente, em declínio, seria responsável por empobrecer e prejudicar a pulsão do sujeito no período edipiano e a dialética das sublimações. Com isso, instalando no berço do neurótico as chamadas "Madrinhas sinistras", a saber, a impotência e a utopia, aprisionando sua ambição (Lacan, 1938/1987, p. 61), ou seja, seu desejo. Por isso a correspondência dessa grande neurose com as depressões na atualidade.
O Complexo de Édipo, como uma coordenada legalizante, ocupa posição privilegiada porque é a base atual de nossas relações com a cultura na civilização ocidental (Lacan, 1957-1958/1999). A família, independentemente de sua composição, tem a sua realidade constituída nas e pelas relações sociais e está condicionada a fatores culturais, que, por sua vez, são organizados dentro da cultura para tentarem dar conta das pulsões e das circunstâncias psíquicas. Dessa forma, constituem-se os processos de subjetivação e objetivação, por meio de um processo dialético, produzindo novas formas de conflitos da família (Lacan, 1938/1987, p. 20). O Complexo de Édipo define as relações psíquicas na família, dando-lhe forma e subordinando as diversas composições sociais familiares da modernidade, marcando todos os níveis do psiquismo do sujeito.

É a partir da situação edipiana e suas vicissitudes causais ou determinantes danosas que a história do sujeito adquire significação e a importância de determinados traços na sua personalidade. Os acidentes que afetam a situação edipiana e sua evolução se repetem nos efeitos do supereu e se refletirão nas formas do ideal do eu. Lacan alerta que não devemos negligenciar o conflito funcional do Édipo na família conjugal, porque ele produz uma dialética social que é reintegrada no progresso psicológico (Lacan, 1938/1987, p. 54). Em contrapartida, uma imago do pai diminuída, declinada, desvia a energia de sublimação de 
sua direção criadora, favorecendo um ideal de integridade narcísico, imaginário e não simbólico. A imago da mãe trai as identificações primordiais, as suas formas e ambivalência marcam o ideal do eu e o supereu, sobretudo na menina. Para essa, a sublimação da imago materna em declínio tende a se transformar em sentimento de repulsa e na exacerbação da preocupação com a imagem especular.

De fato, pai há, ele é o genitor, mas é necessário que o pai, enquanto função simbólica, seja sancionado num significante pela mãe, pois é o nome do pai que cria a função do pai (Lacan, 2005, p. 47). Lacan (1957-1958/1999, p. 180), a partir do Seminário As formações do Inconsciente, aponta que a carência do pai não se encontra nos tipos de pai, mas no nível do pai simbólico, do significante Nome-do-Pai. O que importa é o pai no Complexo de Édipo, o pai na estrutura, o pai simbólico, que é uma metáfora, um significante que substitui outro significante, o significante materno. Não se trata da presença física do pai no ambiente, esse poderá estar ausente, mas do significante Nome-do-Pai, para dar sustentação à lei (Lacan, 1957-1958/1999, p. 152).

A preocupação de Lacan com o declínio do pai não é com o declínio da imago masculina, por não se constituir mais no referente simbólico da função de lei e, para piorar a situação, por não ter claramente um substituto. A consistência da palavra com força de lei é o que demandamos no Outro, que essa palavra tenha consequências e os nomes se tornem simbólicos de uma lei (Jerusalinsky, 2004, p. 11), isso constitui a entrada do sujeito no jogo da linguagem. A metáfora concerne à função do pai simbólico nas relações inter-humanas, situada no inconsciente, "é no nível desse Outro que se situa a dialética do significante, por onde convém abordar a função indutora do Nome-do-Pai" (Lacan, 1957-1958/1999, p. 184), mediador do desejo da criança para além do desejo do Outro materno. É justamente nessa função simbólica do pai que encontramos as carências paternas. $\mathrm{O}$ significante Nome-do-Pai, enquanto o suporte da função simbólica, é uma necessidade da cadeia significante.

A mediação do pai na ordem simbólica é que priva a mãe do objeto de seu desejo, o objeto fálico, desempenha a sua função essencial, ao menos para as neuroses, no Complexo de Édipo. O sujeito infantil se posiciona quanto ao efeito do papel desempenhado pelo pai, o qual vem dizer que a mãe não tem o falo e seus desfechos, o da castração ou da privação. Entretanto, no terceiro tempo, posterior à privação ou à castração, o pai intervém como aquele que tem o falo, possibilitando uma identificação, o ideal do eu (Lacan, 1957-1958/1999, p. 201). Mas o sujeito vai assumir ou não, vai aceitar ou recusar, se a mãe é ou não castrada. A mulher sabe que o falo está do lado do pai e vai em direção a ele. Por isso a dimensão de álibi na verdadeira feminilidade: "Nas verdadeiras mulheres há sempre algo meio extraviado" (Lacan, 1957-1958/1999, p. 202).

O lugar do pai depende de uma disposição materna (Naouri, 2002, p. 242), enquanto mulher. Essa abertura concedida ao pai por uma mulher que se tornou mãe estará diretamente relacionada à onipotência materna. É a castração na mãe fálica que vai proporcionar à metáfora paterna a inscrição no nível simbólico do significante nome-do-pai. É a castração que vai possibilitar o gozo fálico fora do corpo, dentro da linguagem, do lado da Lei da diferença. A lei da proibição da mãe a ser transmitida é o de um lugar terceiro, fazendo o corte nessa ligação mãe-filho (a) e inscrevendo a diferença, é a lógica da exceção exigida e que autoriza o sujeito a desejar, lugar do Nome-do-Pai.

Um sujeito só nasce verdadeiramente quando é representado por um significante para outro significante. O Nome-do-Pai é esse significante essencial, que em torno dele se organizará o jogo dos significantes e inclusive a questão da procriação. O estatuto da paternidade é simbólico e determinado pelo significante Nome-do-Pai. Lacan (19711972/2012, p. 200) até fica enfastiado com essa questão do pai, vai chamá-lo de "é-pater", o pai assombroso, que não tem mais assombrado a família. Entretanto, terá de haver algo que possa cumprir essa função. Mas, como a situação parece irreversível, a questão agora é como fazer o luto dessa imagem paterna para as gerações seguintes e como cessar a sua reivindicação (Julien, 1997, p. 32), sobretudo em forma de sintomas.

\section{ACERCA DO ESTATUTO DO GRANDE OUTRO NA MODERNIDADE}

Para Freud (1930/1991), o mal-estar na cultura é o supereu, com o predomínio das relações narcisistas (Garcia, 1997, p. 76) e a tendência à agressividade autodestrutiva no homem, que é uma disposição pulsional original, o maior impedimento à civilização. Lacan (1948/1998, p. 124) também assinala que a primazia da agressividade, que estamos sujeitos na ordem social atual, é determinante na neurose moderna e no mal-estar da civilização.

Em decorrência da crise do Édipo, os problemas da identificação edipiana narcísica encontram-se na dificuldade ou na impossibilidade do sujeito em transcender a agressividade constitutiva no processo de subjetivação, em detrimento dos efeitos sublimadores. As possibilidades de acidentes e os danos na dialética do complexo edípico, as instituições e os discursos característicos de seu mundo determinam no homem moderno a estrutura do eu e o tom da agressividade correspondente ao modo da identificação narcísica. Ademais, a frustração cultural é o que domina as relações sociais entre os seres.

Melman (2003) postula que, na modernidade, o que está em curso é a foraclusão do Outro. Não há mais o Outro para que se afirme a dimensão de alteridade, suporte da diferença. Ou seja, não há mais a relação entre os significantes $\mathrm{S} 1 \mathrm{e}$ S2, mas sim uma relação entre semelhantes, não há falha 
nesse intervalo, portanto não há sujeito como efeito entre um significante e outro. O sujeito é atópico, deslocado, não encontra seu lugar, não tem voz. Não é mais o sujeito do desejo, sujeito do inconsciente, da enunciação, mas do enunciado.

Nesse contexto moderno, o capitalismo e o laissezfaire promovem a devastação social. Todavia, o que fica comprometido é a função apaziguadora do ideal do eu, que está condicionada à função paterna, de conexão das normatividades da libido com a da cultura. A subordinação do homem à cultura é efeito de sublimação da libido genital, a partir das crises vividas no Édipo. E essa intermediação cultural tem a sua repercussão no que diz respeito ao objeto sexual no Complexo de Édipo (Lacan, 1936/1998, p. 102). Como consequência dessa degradação, ou barbárie social, em se tratando das necessidades subjetivas do homem "liberado" da sociedade moderna, tem-se a "ausência crescente de todas as saturações do supereu e do ideal do eu" (Lacan, 1948/1998, p. 124), realizadas em organizações sociais tradicionais. Isso se demonstra com a abolição dos princípios universais do masculino e do feminino e as incidências psicológicas do fenômeno moderno chamado de a "luta entre os sexos". A sociedade se localiza no limite entre a anarquia democrática das paixões e a tirania narcísica, conduzindo a promoção do eu, condenando o homem moderno, como indivíduo, ao desamparo original, Hilflosigkeit.

As repercussões sintomáticas que caracterizam a sociedade contemporânea são de proliferação de sujeitos submetidos ao imperativo de um ideal narcísico moderno de suposta autonomia, que resta na frieza e no vazio. O estatuto do grande Outro, caracterizado pela precarização do simbólico, embalado pelo discurso capitalista, corrobora a sociedade de consumo, dos gozos imediatos. As tecnologias do mundo moderno favorecem o individualismo e o isolamento dos indivíduos, proporcionando gozos solitários, senão autísticos. É como se o sujeito tentasse realizar o seu fantasma sem mediação, ou seja, sem a mediação da metáfora paterna (Sobral, 2011, p. 12). A mais-valia equivale ao mais-de-gozar e suas consequências devastadoras (Lacan, 1969-1970/1992, p. 100). Vai dizer Lacan (1972/2012, p. 88) que o discurso do capitalismo é a rejeição, a Verwerfung, da castração dos campos do simbólico, isso deixa de lado as coisas do amor. Os objetos tecnológicos estão mais acessíveis e prontos à satisfação, em oposição ao amor, que é dar o que não se tem. Como afirma Melman (2003), há uma preponderância do gozo objetal em detrimento do gozo fálico. O gozo objetal é unissex e favorece a bissexualidade.

A sociedade já não está mais orientada pela dialética do desejo, mas sim pelo imperativo do gozo superegoico (Sobral, 2011, p. 68). Tais efeitos sociais dificultam aos sujeitos realizar o intercâmbio fálico, por conseguinte, a dificuldade e a inaptidão para estabelecer laços afetivos. A possibilidade das relações vivíveis entre homens e mulheres, "de um sexo ao outro, necessita da intervenção desse medium que é a metáfora paterna" (Lacan, 1964/1985, p. 260). As dificuldades, nesse âmbito, são consequências do declínio desse significante no estatuto do Outro contemporâneo. A fragilidade ou a ausência de elementos simbólicos, que proporcionariam identificações que servissem aos homens e às mulheres, denunciam essas carências e a dificuldade do ser humano em se reconhecer nisso tudo.

Com o declínio do Nome-do-Pai, os laços sociais são caracterizados pela incerteza das referências e, por conta disso, os sujeitos se situam num estado limite (Rassial, 2000, p. 27). A contemporaneidade se caracteriza pelo anonimato e pela mobilidade, fazendo com que os sujeitos percam a orientação e a referência de traços culturais aos quais se identificariam para seguir a vida. Esse estatuto está marcado pela passagem da sociedade patriarcal à matriarcal. $\mathrm{O}$ grande Outro da modernidade está mais representado pelas mães, traço que fragiliza e marca o estatuto da feminilidade na contemporaneidade. Porém, vale ressaltar que os novos formatos de constituição dos núcleos familiares, com o predomínio feminino, não se constituem somente pelas conquistas sociais de cidadania, mas parte significativa pelas dificuldades com o amor, com a diferença e com os laços nas relações entre homens e mulheres.

\section{REPERCUSSÕES NO ESTATUTO DA FEMINILIDADE NA CONTEMPORANEIDADE}

A cultura contemporânea favorece ainda mais a confusão entre histeria e feminilidade. A histeria seria a expressão habitual do que se imagina e se espera de uma mulher, bem como se espera que essa histérica manifeste sua feminilidade (Melman, 2001, p. 14). É evidente como a forma de um sintoma se adapta às condições e contextos sociais da época. O sujeito, fruto desse Outro de seu tempo e meio, é construído na articulação entre o laço e os significantes dos discursos sociais no qual está imerso. Nos séculos passados, os lugares reservados socialmente às mulheres, os ideais de feminilidade, eram o do casamento, de uma esposa dedicada ao marido, às atividades domésticas e o da maternidade (Backes, 2008, p. 59). Entretanto, a maternidade ainda persiste, mas o casamento está em crise.

Apesar também do declínio do amor cortês, o sonho secreto de viver um romance amoroso ainda resiste. Contudo, é uma dificuldade, senão uma impossibilidade da histérica, que se exacerba na atualidade, de ocupar o lugar de objeto na fantasia de um homem. Mantendo a essência da estrutura histérica, a do desejo insatisfeito.

A mulher moderna, que usufrui dos resultados das lutas pelos direitos sociais de igualdade e liberdade, de 
legitimação de sua cidadania, é mais independente, realizada profissional e financeiramente e não mede esforços em busca da satisfação imediata. Esse é mais um dos estereótipos da mulher contemporânea. Entretanto, essa liberdade toda também a leva à solidão e, apesar de todas essas conquistas, isso não supre a dependência "identificatória na ordem do ser" (Zalcberg, 2007, p. 56), isso continua uma questão aberta para uma mulher.

Nessa conjuntura, podemos vislumbrar a máscara da feminilidade contemporânea que postula o seu estatuto. As mulheres e suas competências sublimatórias pretendem e apresentam-se na esfera do social como a figura imaginária de uma supermulher, com a busca de atributos nada modestos, tais como o da mulher perfeita e, para isso, a exigência tirânica superegoica do ter que ser uma mãe, uma esposa e uma profissional "perfeitas", etc., estão potencialmente falicizadas e, contrariamente, os homens se encontram desvirilizados. Entretanto, há um preço alto a pagar por essas condições a ambos. As mulheres, nessa forma de ser, em um posicionamento lógico, demonstram o movimento de se igualarem aos homens, senão de superá-los e desfalicizá-los. A defesa do individualismo, da autonomia e a realização profissional acabam contribuindo com o prescindir do outro.

As mulheres são marcadas por infelicidades muito pontuais, porque a suposta felicidade se localizaria num campo muito sensível e importante às mulheres, de seu gozo mais precioso, que lhe é singular e em que se localiza o furo no simbólico, que implica a dimensão do amor, o sonho de amor por seu parceiro. Tanto é assim que a queixa mais comum entre elas estaria nas relações fracassadas com os homens e, como elas mesmas dizem, sobretudo, da "falta" de homens (Guimarães, 2012, p. 13). Claro que não se trata de falta de homens, mas de manutenção do pai idealizado, que não é castrado, imposto pelo supereu materno, com o qual estão muito ocupadas a ponto de não estarem disponíveis aos homens. Por isso, nenhum homem está à altura. As mulheres, querendo ser mais potentes e fálicas que os homens, não favorecem ao efeito feminino de fetiche que despertaria o desejo no homem. Isso gera tristeza nas mulheres, porque não favorece o amor.

Um fato que marca e ilustra uma dessas facetas da máscara da feminilidade contemporânea está no discurso do "politicamente correto" (Guimarães, 2012, p. 41), que elas tentam impor nas relações com seus parceiros. Assim, impõem tanto a forma como deve ser como pai, quanto como deve ser como homem. Isso nada mais é do que a crença de que "O" homem existiria, basta retificá-lo um pouco no seu jeito de ser (Garcia, 1997, p. 28).

As incidências clínicas do matriarcado que se tornam comuns hoje em dia se localizam na disposição e na dificuldade apresentada pela mãe para transmitir o falo aos filhos, sobretudo ao menino, porque a sua feminilidade é posta em causa (Melman, 2001, p. 16). Isso a remete à sua castração, ou às suas feridas abertas em relação a não ter o falo. Quando a mãe usurpa o falo do menino, ele tende a ficar transtornado. Contudo, para a menina, as evidências são mais exacerbadas ainda, pois as filhas esperam sempre da mãe o reconhecimento de sua feminilidade. No contexto atual, as condições não facilitam à mãe abrir mão de sua condição de mãe-fálica, dificultando à menina o acesso à feminilidade. Esse contexto favorece, assim, os desastres, senão as devastações e os dramas de reivindicações obsedantes e recíprocas.

Com o predomínio do matriarcado, Melman (2001, p. 16) assevera a produção considerável de certos sintomas, sobretudo sexuais, para meninos e meninas, em função da mãe representar e assumir a instância fálica, conforme as configurações das máscaras que isso exige na contemporaneidade. O estatuto do grande Outro se encontra representado fortemente pelas mães e tem como condição crítica a dimensão da falta (Sobral, 2011), condição postulada como uma das características do estatuto da feminilidade na contemporaneidade. A literatura psicanalítica assinala que as dificuldades que uma filha tem com a feminilidade estão mantidas desde o lugar do Outro materno. A presença maciça da mãe reforça para a filha a crença de que ela vai receber de sua mãe a feminilidade. Dificultando, com isso, ou impedindo a separação da ligação mãe-filha (Zalcberg, 2007, p. 49).

Podemos afirmar que a mãe moderna, que sofreu as consequências dos declínios paternos e suas mediações, apresenta dificuldade em transmitir a falta ou não a transmite. Apresenta dificuldades em querer ver sua filha tornar-se uma mulher. Ela quer ser não só necessária à filha, mas que a filha dependa dela para tudo. Não dão um passo na direção de um possível corte nessa relação engolidora. Isso é um fato clínico, é um fenômeno que tomou uma dimensão crítica na atualidade. Basta escutarmos as dificuldades que as mulheres em análise apresentam para fazer o luto da forma como essa relação mãe-filha foi concebida, da qual são cúmplices. São tomadas de um sentimento de culpa devastador, não obstante as filhas temerem ser ou tornar-se igual a mãe.

Essas dificuldades apresentadas por algumas mães são correlatas ao Édipo e, mais precisamente, à sua posição em relação à castração e à sua feminilidade, não bem resolvidos. Portanto, quando se trata de uma filha mulher, as coisas ficam muito mais difíceis, porque a presença de uma filha atualiza para a mãe as suas questões da feminilidade e a remete à sua própria história com sua mãe. O fenômeno é transgeracional e o que se repete é o fracasso. Curiosamente, não são os homens que oferecem ameaça ao mundo feminino, mas as mulheres que se devoram entre si na iniciação das etapas da vida enquanto filha, mãe e avó, sobretudo para a menina na afirmação de sua identidade de mulher (Eliacheff \& Heinich, 2004).

Com a prevalência das famílias matriarcais, a mãe acaba ficando no "lugar do Outro do gozo". Lacan (19691970/1992, p. 105) chamará atenção para a importância do papel da mãe, principalmente quanto ao desejo da mãe, afirmando que nenhum sujeito está livre disso. Assinala que o desejo da mãe não é algo que se suporta de forma indiferente, sem consequências, porque esse desejo 
acarreta sempre estragos. Utilizando a metáfora da bocarra do crocodilo, como se expressa em relação à mãe e a seu filho, Lacan dirá que a bocarra está em geral sempre aberta e disposta a engolir o sujeito, em razão do desejo e gozo da mãe. Mas isso poderá ser evitado somente por quem tem potência para enfrentá-la, pelo falo, pelo pai, no nível da metáfora paterna. Mas é justamente nesse nível que a estrutura fica comprometida.

O estrago materno terá os seus efeitos mais danosos, sobretudo nas relações nas quais a mãe tem a filha como seu objeto de gozo (Sobral, 2011, p. 21). Essa condição não favorece o espaço e as condições necessárias à transmissão da falta à filha. Esta estará condenada e sufocada à condição de filha, em função da dominação do "amor" materno. Dessa forma, não encontrará espaço para tornar-se uma mulher, pois terá o desejo comprometido e corroborado também pelo Outro social, que vai empurrá-la ao encontro das satisfações narcísicas e infantis, que a modernidade oferta em demasia.

O estrago materno condiciona o sujeito a uma posição subjetiva, na qual o desejo fica prejudicado, senão impedido, aprisionando o sujeito no desejo do Outro da infância. Essa mãe, com suas dificuldades em permitir a entrada e o reconhecimento efetivo do pai simbólico, que faria o corte na relação mãe-filha, acaba impedindo a transmissão da falta que daria lugar ao desejo. Nesses casos, acaba favorecendo a fixação da filha numa posição de gozo, mas de um eu ideal. Assinalamos, com isso, que as mulheres estão mais distantes da falta, do desejo e de um gozo que lhes concerne. $\mathrm{Na}$ clínica, encontramos essas questões manifestas nas anorexias, bulimias, depressões pós-parto, depressões e estados maníacos que grassam na atualidade.

A função paterna precária, com pouca operatividade, proporciona poucos recursos simbólicos para o sujeito ao aparelhar o gozo. O sujeito acaba não tendo elementos simbólicos significantes na sua estrutura que lhe possibilite indagar sobre o desejo do Outro. Em conseqüência disso, encontramos os sujeitos mulheres mais carentes ou desprovidos da alienação significante, por isso acabam ocupando mais facilmente, mas não sem sofrimento, uma posição de objeto de desejo da mãe, de objeto da demanda da mãe, sujeitas e submissas às imposições e injunções dessa mãe (Guimarães, 2012, p. 66), submissão incondicional ao supereu materno. Evidentemente estarão mais competitivas em relação aos homens e mobilizadas pelo imperativo superegoico de um gozo insaciável (Sobral, 2011, p. 22).

Outro aspecto importante apontado por Guimarães (2012, p. 33), em decorrência do declínio paterno na esfera do amor, é o declínio do amor pelo pai. Isso se dá em razão das dificuldades da transferência do Édipo, das relações pré-edípicas da menina com a mãe para o pai, de quem a menina esperaria o saber sobre como ser amada e ser mulher, apaziguando a devastação materna. Esse amor paterno perde a qualidade e é colocado em cheque. Em decorrência disso, encontraremos, nas mulheres, em suas neuroses, a imago de um pai ainda mais "erotizado" do que um pai de amor, que enlaçou o gozo ao amor, ampliando com isso a vertente devastadora articulada ao gozo feminino.

No Édipo das meninas, é o amor ao pai que vai proporcionar a elas as fantasias inconscientes de sedução do pai, sendo esse como agente. A busca de uma mulher por um parceiro amoroso e sexual é resultado da sua relação nos primórdios com o pai, que o olhar do companheiro seja desejante e não incestuoso, que não a remeta à culpa por ser mulher (Calligaris, 2005, p. 19). "É o amor do pai que proporcionará a envoltura do gozo feminino. Quando esse amor do pai é questionado ou perde sua consistência, a devastação pode produzir-se como o efeito essencial da mortificação superegoica no gozo feminino" (Guimarães, 2012, p. 33).

Outra característica marcante da máscara da feminilidade contemporânea está articulada ao que Guimarães (2012, p. 26) denominará de paradoxo do supereu e suas duas vertentes, isso ainda dentro do campo do amor. Por um lado, é o imperativo superegoico de gozo no qual as mulheres se firmam no "não se apaixone", que é o não se apaixonar por um homem, enquanto defesa em relação ao gozo feminino, que equivaleria a uma ameaça ao seu posicionamento fálico. Por outro lado, isso é uma tentativa de rechaçar justamente o que lhe é precioso: o se apaixonar, que seria viver o seu sonho de um grande amor, de uma mulher frente a um encontro com um homem, que, por sua vez, é o encontro com esse Outro que ela é. Seria justamente o se entregar a esse gozo feminino, que a invade e a sensibiliza e que por isso lhe é caro. Justamente porque aí se situa a ausência de si mesma, de sujeito, na sua parte não-toda. As mulheres fazem do amor uma causa. Como atualmente o amor está em crise, ela acaba ficando sem causa, como postula Zalcberg (2007, p. 151). Essa defesa superegoica tentará, com sucesso ou não, refutar a possibilidade de ser amada por um homem, de se fazer causa de seu desejo.

Lembremos que Lacan apontou que elas não se sentem bem na posição de objeto ("a") para o homem. Esse gozo superegoico do "não" à paixão vem corroborar a manutenção de um eu ideal de "A Mulher," que não existe. Entregar-se a um amor seria justamente reconhecer-se faltante. Lacan (1972-1973/1985, p. 118) apontou que o gozo feminino não se ocupa do homem de modo algum. Essa mulher está submersa na vertente do gozo feminino que tem a solidão como sua parceira. Portanto, a patologia devastadora que tem invadido as mulheres não é necessariamente a da paixão amorosa, que não é menos devastadora, mas a do supereu (Guimarães, 2012, p. 27), que se traduz no medo avassalador da perda do amor, de não serem amadas, como disse Freud (1931/1974). Esse temor é oriundo da dificuldade que a menina apresenta em deixar de ser o objeto fálico para a mãe, porque está identificada a ele (Zalcberg, 2007, p. 46). A perda do amor a remete à perda de si mesma. Pois, através do amor de um homem, com o que ele lhe diz, ela poderá se reconhecer ser esse Outro. 
Enfim, a mulher apaixonada que morria de amores por seu homem está sendo excluída ou recalcada das facetas da mascarada na atualidade. Agora, se ela sucumbe a uma paixão, a máscara cai por terra e os conflitos vêm com as exigências superegoicas de juras de amor exclusivo e eterno. Se o amor não é correspondido, as autorrecriminações e as culpas serão violentas ou insuportáveis. O pai mais erotizado que amado não lhe transmite a segurança da crença de ser a única e exclusiva através do amor dele.

Ambivalência da mãe, ambivalência da filha, respectivamente, a primeira impede ou estimula a filha a tornar-se mulher para um homem, a segunda fica entre uma escolha de objeto, ficar entre a condição de ser mulher para seu parceiro ou na manutenção da condição de filha para a mãe. De qualquer forma, se a mãe é presente em demasia ou ausente, essas relações difíceis produzirão filhas mal equipadas para caminharem na direção de uma feminilidade. A tendência é buscarem um homem, por vezes o estereótipo do pai, mas com as características da mãe para continuar dialogando com ela, ou ainda estabelecerem relações impossíveis com os homens, julgando-se eternas fracassadas.

A considerar essas perspectivas dos estatutos do Grande Outro e da feminilidade, observamos que a dominação materna sobre as filhas, que se tornou tão pesada nos últimos tempos, dificulta às mesmas se libertarem dessa ligação com a mãe, corroborado pelo sofrimento infligido pela culpa atroz em supostamente pensar em trair tal relação, minimamente $o$ suficiente para seguirem as suas buscas solitárias no processo de feminilidade, na busca de ser uma mulher e, em alguns casos, até de conseguirem sustentar um relacionamento amoroso com um homem sem as devastações.
As evidências clínicas e fatos sociais assinalam a dificuldade e/ou o desinteresse pelo casamento, os divórcios e a precariedade dos laços afetivos entre os casais, embora ainda continuem a se constituir. Valemo-nos da crítica que Naouri (2002, p. 263) faz aos casais que não se compõem e aos que se decompõem e às famílias desmanteladas na contemporaneidade. Atualmente, não há a tentativa de se recompor de maneira diferente, sustentando, com isso, o que ele denominou de "o culto ao pós-pós-moderno da individualidade", satirizando essa tendência e lamentando, ao mesmo tempo, as decomposições, enfraquecendo as montagens que as culturas lutaram e mataram para estabelecer ao longo da vida, para tentar dar conta da diferença e da sua irrepresentabilidade. Isso também tem relação íntima com todo o esforço e trabalho, senão a dificuldade de uma mulher para a realização de uma feminilidade.

Em decorrência desse estatuto do Outro na modernidade, $o$ que encontraremos é essa tendência ao rechaço à feminilidade (Sobral, 2011, p. 21), não há castração, justamente porque há uma prevalência de uma posição fálica, senão masculina, das mulheres, chamadas psicanaliticamente de a mascarada. As mulheres, na tentativa de rechaçar a feminilidade, de aceder a uma posição feminina, enquanto objeto, causa do desejo de um homem, segundo Lacan, agregados a isso, o casamento e a maternidade acabam sucumbindo em seus sintomas, nessa tentativa de se fazerem fálicas de todas as formas possíveis, do lado do todo, em referências às formulas da sexuação. Backes $(2008$, p. 64) sugere que essa posição de extrema exigência e sacrifício seria a exacerbação moderna do Penisneid e Chamorro (2011, p. 116) conclui que a metáfora da falta de pênis é o gozo feminino.

\section{CONSEQUÊNCIAS DOS ESTATUTOS NA MATERNIDADE}

A maternidade pressupõe a elaboração de uma ferida, resultada da especificidade dessa relação mãe-filha, cheia de cumplicidade e sujeita à dominação da mãe. O tornar-se mãe é uma questão de transmissão. Um dos traços efetivos ou que fica como resto da feminilidade, enquanto sintoma da mulher, é a maternidade. Contudo, para atingir esse objetivo, elas já prescindem da relação amorosa efetiva com um homem e até mesmo de um instituto mais tradicional e conservador, como o casamento, para engravidar e para se sentir mulher e mãe. Esse caminho mais curto favorece ao gozo feminino, o do imperativo superegoico, em detrimento de uma feminilidade e é uma tendência crescente de como as mulheres podem evitar cada vez mais os homens (Zalcberg, 2007, p. 21), mas que responde enquanto efeito e manutenção do estatuto desse Outro na contemporaneidade.

Hoje se pode comprar um bebê em laboratório, o verbo é pesado, mas com o advento da fertilização in vitro, das técnicas de reprodução assistida, dos bancos de sêmen e de doadores desconhecidos, isso se tornou realidade. Há até mesmo voluntários inconscientes, via método natural, nas apostas dos encontros amorosos contingenciais. As dificuldades da mulher em lidar com esse estilo e ritmo dos encontros mais sexuais do que amorosos, vividos na modernidade, é porque, no fundo, a mulher busca o amor, encontros causais, que se referem à causa de seu desejo e não encontros sexuais casuais. Estamos em um tempo em que a paternidade depende do desejo de uma mulher e talvez do seu laço conjugal. Uma das vicissitudes da paternidade, nos dias de hoje, a participação de um pai, é que ele pode ser reduzido ao real do espermatozoide (Giongo, 2005, p. 62). Isso demonstra que as mulheres estão tendo o poder de decidirem sozinhas sobre a procriação, designando um pai ou excluindo-o. A instituição da paternidade nos dias de hoje está no poder das mulheres. A cultura tem contribuído para isso, colocando os homens numa posição de descartáveis.

Entretanto, há um movimento simbólico muito expressivo nos dias de hoje, manifestando essa demanda simbólica de reconhecimento que vem dos filhos que exigem o exame de DNA para reconhecimento de paternidade, por não suportarem ficar com o buraco de uma função simbólica 
em sua história. $\mathrm{O}$ exame é exigido porque vem de outra instância, jurídica, que determina, por meio da autoridade, que faltou um nome, uma origem, um pai, um endereço a se referenciar.

Um filho acaba tendo o lugar de objeto condensador de gozo da família e da sociedade. O sintoma da criança é correlato ao sintoma na estrutura familiar, podendo representar a verdade dos pais. A tendência da nova estrutura familiar, independentemente da composição, com suas funções simbólicas e imaginárias, é localizar-se na sua estrutura que se sustenta e se organiza em torno do bebê como objeto a, como objeto de gozo. Por isso, resgatamos a importância da vivência e da história do Édipo para uma criança. Lacan (1969/2003, p. 369) assevera que, na preponderância da fantasia da mãe, que tem como sintoma um filho, reduz-se muito a articulação, porque vai prevalecer o sintoma decorrente da subjetividade dessa mãe. Isso ocorre quando o Nome-do-Pai não cumpre de forma eficaz a sua função de mediação. Nessa condição, a criança não vai se perguntar sobre o desejo da mãe, que estaria como um enigma, deixando, assim, a criança exposta às capturas fantasmáticas.

A mãe da contemporaneidade é uma mãe angustiada. Esse bebê, que é feito objeto a na família, produz mães e pais angustiados por condensarem esse gozo (Guimarães, 2012, p. 62). Os pais, na condição de mães coadjuvantes, às vezes acabam cumprindo funções que seriam desejáveis que fossem realizadas pelas mães, por elas estabelecerem vínculos primários na relação mãe-bebê muito importantes no início da vida. Ocorre porque a mãe angustiada é justamente aquela que tem dificuldades com o desejo, isto é, ou ela não deseja, em função de suas dificuldades com a falta, com sua feminilidade e com a maternidade e, por conta disso acaba atendendo, sim, a uma demanda. Isso é fato, tanto que há casos de mães deprimidas alegando discursivamente que não desejavam ter um filho naquele momento, que não o haviam programado, ou ainda que a oferta do seu bebê à mãe, que se tornaria avó, já não teria mais sentido e etc. Nesses casos, o risco é a desvinculação da relação mãe-bebê.

Ocorre que certos pais, sobretudo a mãe, no contexto do estatuto da modernidade, vivenciam, com muito sofrimento, nos níveis fantasmáticos, o nascimento do bebê, em razão de suas próprias dificuldades desencadeadas quando da revivescência de suas histórias edípicas falhas e com suas identificações precárias, além dos remanejamentos na linhagem familiar, dificultando a esse bebê um lugar na fantasia materna, senão no discurso familiar. Freud diz que somente com a maternidade a mulher passa do narcisismo, do passivo ser amada, ao amor de seu objeto, a um filho, enquanto falo (Freud, 1917/1976). Mas, com narcisismo frágil, senão falicizado e superpotente e as condições sociais difíceis da modernidade, quando do nascimento de um filho, a mãe, durante a gestação e, sobretudo, no pós-parto, encontra-se tanto quanto o bebê na condição de desamparo. A impotência e a incapacidade de investir o próprio narcisismo no filho e, por conseguinte, a renúncia aos cuidados maternos dos quais ela é tomada (Boukobza, 2002), revela, por vezes, uma depressão pós-parto ou um Baby Blues, expondo o bebê às devastações mais danosas num período tão importante da vida.

Agora, considerando os entraves decorrentes dos estatutos do Outro e da feminilidade, podemos lançar alguns questionamentos, como: No que se transforma o desejo dessa mulher por um homem e o desejo de ter filho? Numa depressão pós-parto? A função se restringiu à procriação? (Licht, 2002). Nesses casos, um filho vem para tentar suprir uma carência materna que nunca chegou à castração. Ainda que encontremos saídas, os bebês não estão isentos das devastações provocadas na maioria dos casos.

Enfim, é pertinente destacar que a gestante torna-se também gestante do pai dessa criança, mas a gestação do pai é de uma relação com o inconsciente e depende de sua história edípica de mulher e de sua disposição materna (Naouri, 2002, p. 245). Essa história é de uma relação a três. Claro que, se uma filha que se tornou mãe está aprisionada à sua mãe, não haverá espaço para o lugar do pai ou do terceiro. Portanto, ser mãe é ajudar o filho a ter acesso ao pai, tanto no sentido simbólico da função, quanto na relação do homem com seu filho. Agora, se o homem e a mulher estão vivendo a luta dos sexos, a disputa pelo poder, atuando a sua não aceitação da castração simbólica, restará ao filho sofrer os danos desse conflito que entrava o Édipo. Se o filho permanece na posição de falo da mãe, não tem como ele pagar a dívida simbólica necessária para ter acesso à ordem simbólica da cultura (This, 1987, p. 205). Entretanto, nos dias de hoje, no caso das famílias recompostas, a concessão da função paterna, função simbólica de referência, ao outro novo parceiro que não o genitor, amado por ela, seria de grande benefício para uma criança.

\section{CONSIDERAÇÕES CONCLUSIVAS}

Abordamos pai e mãe enquanto funções. O pai, enquanto uma função simbólica, efeito de estrutura, sobretudo no desejo da mãe em declínio e a mãe enquanto uma função simbólica e real, quanto ao amor para a criança. A importância do papel da mãe é indiscutível e verdadeiro e se constitui no Outro real da primeira dependência. É a relação mais direta das relações, o bebê vai conferir o poder à mãe, porque é ela quem o satisfaz ou a quem cumpre essa função. Desse poder imenso, talvez, na vida adulta, nunca consiga se livrar.

É com a lógica da estrutura que tropeçamos. Estrutura de uma mãe que, por sua vez, estrutura uma lalangue numa criança, pois é ela quem detém o poder sobre a vida e a morte dessa criança - assim vivido pelo infans. A relação 
mãe-bebê está aberta à vertente perversa do desejo, na qual a carência materna faz do bebê seu objeto, quando não chegou à castração. Chamamos atenção para esse ponto, quando se trata de rever os efeitos abusivos do que se chama de amor materno, a resistência suscitada, senão a intolerância é tão feroz quanto a agressividade que se revela no estatuto do Outro na contemporaneidade. Ou seja, o quão o sujeito ainda abriga e defende a lalangue - a língua dita materna, campo de afetos que constrói o sujeito -, a manutenção da mãe fálica. Noli tangere matrem, disse Lacan (1963/1998, p. 802).

Assinalamos que a clínica individual responde à clínica social (Chemama, 2007, p. 174), pois o sintoma individual do sujeito é uma proteção a uma patologia social, do discurso que organiza o laço social. O declínio da função paterna prejudica, na estruturação dos sujeitos, a pulsão, a sublimação na direção criadora e o desejo, favorecendo um ideal narcísico imaginário, em detrimento do simbólico, o gozo não fica regulado pela autoridade paterna legiferante.

Eliacheff e Heinich (2004, p. 193) assinalam que a falta do terceiro elemento, o pai, a função simbólica, o corte na relação mãe-filho é evidente nos meninos e inexprimíveis nas meninas e redefinem o incesto para os dias de hoje como todo tipo de relação na família que faz dois e não três, em que deveria estar o terceiro. A importância que um pai tem para uma mãe é o que ela transmite à sua filha. Embora a função simbólica do pai não seja resolutiva para o Édipo da menina e sua feminilidade, encaminha para a possibilidade de não se fixar na relação pré-edipiana de ligação mãe-filha, abrindo espaço entre elas, favorecendo ao direcionamento da filha ao pai, para posteriormente se dirigir a um homem, abrindo espaço para o campo do amor. A função do pai está condicionada a uma história de mulheres, mas a três, com a presença do terceiro. Mas essa função só é concedida pela mãe da criança, assim como também o poder de anulá-la conforme sua disposição. Como vimos é o nascimento do sujeito que está em jogo.

É nesse contexto do discurso capitalista, como determinante de subjetividades e sociabilidades e do declínio da função paterna simbólica e suas consequências que o grande Outro contemporâneo é marcado pelo esvaziamento de seu lugar Outro. Isto é, na perda dos significantes primordiais, como vimos, de homem e mulher. A anatomia subjetivada no campo do Outro e pelo desejo do Outro marca essa destinação (Chamorro, 2011, p. 113) e o surgimento de novas modalidades subjetivas. As consequências desse Outro sobre a vivência do Complexo de Édipo e as possíveis repercussões desastrosas favorecem as identificações narcísicas, suscetíveis às manifestações agressivas e à rivalidade.

O estatuto da feminilidade na atualidade é correlato ao do grande Outro. A ascensão do matriarcado implica a presença maciça das mães sobre os filhos, expondo especialmente uma filha ao estrago materno, favorecendo a identificação ao objeto fálico do desejo da mãe. Nesses casos, a tendência é a exacerbação do gozo feminino. As conquistas sociais por meio das sublimações não suprem as suas dificuldades com a identificação como ser mulher, isto é, na constituição de uma identidade no desenvolvimento de sua feminilidade. As manifestações sintomáticas denotam que as mulheres não estão encontrando limites adequados para o gozo mais além do falo pelo qual podem ser tomadas (Zalcberg, 2007, p. 146).

As conquistas do mundo moderno e os ideais imperativos que empurram e atropelam a mulher para o ser e o ter atributos fálicos afastam-na de sua subjetividade, está mais difícil para ela ser mulher. Esses ideais não a favorecem em sua feminilidade, ao contrário, fomentam a crença na mascarada e no jogo fálico. Essa crença resta no vazio, porque a sua verdade subjetiva não se esgota no falo (Sobral, 2011, p. 19).

$\mathrm{O}$ estatuto da feminilidade na contemporaneidade aponta na direção da dependência da filha em relação à sua mãe, em função do aumento de poder do matriarcado, favorecendo a manutenção dessa ligação mãe-filha, o que implica a não abertura de espaço para o terceiro, dificultando, com isso, a separação dessa ligação e a feminilidade. O supereu é justamente a prevalência dessa identificação narcísica e não faz corte nessa relação. Ele aparece justamente no lugar no qual a lei falhou. Lacan apontou que esse supereu não é uma função imaginária, mas uma função que não está regulada, não conhece seu limite, é imperativo de gozo, é sádico. O gozo feminino é esse supereu insaciável, gozo sem limites. Nesse gozo não haverá espaço para a lei da metáfora paterna, não entra a diferença. Em síntese, em função do imperativo superegoico do gozo feminino, teremos o rechaço à feminilidade.

Considerando o efeito do declínio do amor do pai, somado ao imperativo superegoico do não à paixão e à crise do amor nos dias de hoje, as coisas ficaram mais complicadas, sobretudo para as mulheres, porque fazem do amor uma causa para sustentação fálica. Como esse amor está em falta, a mulher acaba ficando sem causa. O sonho de viver o grande amor de sua vida com um homem parece se arrastar nostalgicamente com traços melancólicos, embalado pela cultura de insatisfação.

Outro ponto essencial a ser considerado em relação a isso tudo é a dificuldade, sobretudo para a menina, em renunciar a ser esse objeto fálico para a mãe, em função do medo que a consome de perder o amor da mãe. Isso dificulta fazer o luto dessa relação mãe-filha, que por vezes pode se arrastar melancolicamente, senão manifestar agressividade reativa. Por isso Lacan (1964/1985, p. 260) disse que o amor se coloca nesse mais além, em que o sujeito renuncia a seu objeto da fantasia que foi constituído pela lalangue.

Para os pais, o momento do nascimento de um bebê atualiza as suas histórias edípicas. Com esse estatuto da feminilidade na contemporaneidade, podemos nos perguntar, uma vez que a castração implica renúncias, como uma puérpera, que está sujeita a essas destinações, conseguirá disposição para dar conta do tornar-se mãe? Ademais, podemos perguntar acerca dos deslocamentos e renúncias que isso tudo implica e que ela terá de fazer, em maior ou 
menor grau em sua vida e acerca da capacidade para se empenhar na dedicação aos cuidados maternos que um bebê real necessita. A resposta seria: as mulheres enfrentam essa situação com muita angústia, senão fazendo baby blues ou em casos mais graves, desencadeando uma depressão pós-parto, do contrário, não querem ter filhos.

Portanto, no mundo atual, as dimensões do desejo, por sua vez, a produção de demandas e a organização das pulsões e do simbólico estão prejudicados, pois o discurso capitalista rechaça a castração, a diferença e a falta, impedindo o sujeito de estar submetido efetivamente à ordem simbólica e ao significante Nome do Pai. O sujeito carece dessa amarração que viria impor limites ao gozo. Consequentemente, tem-se uma preponderância do imaginário e do gozo voltado aos objetos acessíveis no mundo do consumo, em detrimento da fantasia que sustenta o desejo.

\section{REFERÊNCIAS}

Backes, C. (2008). A clínica da "nova" histeria. In C Backes, A. Costa, C. Cumioto, \& G. S. Pinho (Orgs.), A clínica psicanalitica na contemporaneidade (pp. 59-67). Porto Alegre: Editora UFRGS.

Boukobza, C. (2002). O desamparo parental perante a chegada do bebê. In L. M. Bernardino, C. Mascarenhas, \& F. Rohenkohl (Orgs.), O bebê e a modernidade: abordagens teórico-clinicas. São Paulo: Casa do Psicólogo.

Calligaris, E. R. (2005). Prostituição: O eterno feminino. São Paulo: Escuta.

Chamorro, J. (2011). Las mujeres. Buenos Aires: Granma Ediciones.

Chemama, R. (2007). Depressão, a grande neurose contemporânea. Porto Alegre: Ed. CMC.

Eliacheff, C., \& Heinich, N. (2004). Mães-filhas: Uma relação a três. São Paulo: Martins Fontes.

Freud, S. (1974). Sexualidade feminina. In Edição standard brasileira das obras psicológicas completas de Sigmund Freud (Vol. XXI, pp. 257-279). Rio de Janeiro: Imago. (Originalmente publicado em 1931)

Freud, S. (1976). As transformações do instinto exemplificadas no erotismo anal. In Edição standard brasileira das obras psicológicas completas de Sigmund Freud (Vol. XVII, pp. 157-166). Rio de Janeiro: Imago. (Trabalho original publicado em 1917)

Freud, S. (1991). Das Unbehagem ind der Kultur. In Sigmund Freud Gesammelte Werke. Werke aus den Jahren 1925-1931 (Bd. XIV, pp. 419-506). Frankfurt am Main: S. Ficher Verlag. (Trabalho original publicado em 1930)

Garcia, G. L. (1997). Política do Sintoma. São Paulo: Hacker Editora.

Giongo, A. L. (2005). Ex-pai? A masculinidade. Revista da Associação Psicanalítica de Porto Alegre, VI(28), 61-70.

Guimarães, L. (2012). El estatuto de la feminidad en nuestros días. In Logos 7 (pp. 7-92). Buenos Aires: Grama Ediciones.

Jerusalinsky, A. (2004). Perfurações. A diferença sexual. Revista da Associação Psicanalítica de Porto Alegre, 27, 9-17.

Julien, P. (1997). A feminilidade velada: Aliança conjugal e modernidade. Rio de Janeiro: Companhia de Freud.

Lacan, J. (1985). O Seminário, livro 11: Os quatro conceitos fundamentais da psicanálise. Rio de Janeiro: Jorge Zahar Editor. (Trabalho original publicado em 1964)

Lacan, J. (1985). O Seminário, livro 20: Mais, ainda. Rio de Janeiro: Jorge Zahar Editor Ltda. (Trabalho original publicado em 1972/1973)
Lacan, J. (1986). O Seminário, livro 1: Os escritos técnicos de Freud. Rio de Janeiro: Jorge Zahar Editor Ltda. (Trabalho original publicado em 1953/1954)

Lacan, J. (1987). Os complexos familiares na formação do individuo. Rio de Janeiro: Jorge Zahar Editor Ltda. (Trabalho original publicado em 1938)

Lacan, J. (1992). O Seminário, livro 17: O avesso da psicanálise. Rio de Janeiro: Jorge Zahar Editor Ltda. (Trabalho original publicado em 1969/1970)

Lacan, J. (1999). O Seminário, livro 5: As formações do inconsciente. Rio de Janeiro: Jorge Zahar Editor Ltda. (Trabalho original publicado em 1957/1958)

Lacan, J. (1998). O estádio do espelho como formador da função do eu tal como nos é revelada na experiência psicanalítica. In Escritos. Rio de Janeiro: Jorge Zahar Ed. (Trabalho original publicado em 1936)

Lacan, J. (1998). A agressividade em psicanálise. In Escritos. Rio de Janeiro, Jorge Zahar Editor Ltda. (Trabalho original publicado em 1948)

Lacan, J. (1998). Kant com Sade. In Escritos. Rio de Janeiro: Jorge Zahar Ed. (Trabalho original publicado em 1963)

Lacan, J. (2003). Nota sobre a criança. In Outros Escritos. Rio de Janeiro: Jorge Zahar Ed. (Trabalho original publicado em 1969)

Lacan, J. (2005). O simbólico, o imaginário e o real. In Nomes-doPai. Rio de Janeiro: Jorge Zahar Ed.

Lacan, J. (2012). O Seminário, livro 19: ... Ou pior. Rio de Janeiro: Jorge Zahar Editor Ltda. (Trabalho original publicado em 1971/1972)

Licht, R. W. (2002). Uma pergunta pelo pai. In Psicanalisar hoje, Revista da Associação Psicanalítica de Curitiba, VI(6), 159-164.

Melman, C. (2001). O matriarcado. In Textura - Revista de Psicanálise, 1(1), 13-16.

Melman. C. (2003). Novas formas clínicas no início do terceiro milênio. Porto Alegre: CMC Editora.

Naouri, A. (2002). As Filhas e suas mães. São Paulo: Martins Fontes.

Rassial, J-J. (2000). O sujeito em estado limite. São Paulo: Companhia de Freud.

Sobral, G. (2011). Madres, anorexia y feminidade - Dificuldades estructurales y próprias de la época em relación a los avatares del devenir mujer. Buenos Aires: Ediciones del Seminario.

This, B. (1987). O pai: Ato de nascimento. Porto Alegre: Artes Médicas.

Zalcberg, M. (2007). Amor paixão feminina. Rio de Janeiro: Elsevier. 